\title{
Research on the Management Mode of School Libraries in the Internet Age
}

\author{
Xiaofeng Cai \\ Jiangsu Vocational Institute of Commerce, Nanjing 211100, China
}

Keywords: Internet age; school library; management model

Abstract: Information technology in the Internet era has been widely used in all walks of life, and has had an important impact on the management of school libraries. School library managers can only actively explore new management models in light of the influence of the Internet era, gradually highlight the advantages of the library development process and effectively protect the overall development of the library. Therefore, in combination with the actual situation of the Internet era, it is required to actively develop a more scientific and rational library management model, improve the comprehensive level of library reader services, and lay a solid foundation for the modernization of school libraries.

\section{Introduction}

In the context of China's comprehensive "Internet + " construction ideas, the development of school libraries began to actively explore the construction of new management models, and based on the application of Internet technology, the various technologies in the school library management process were properly Standardization, a more scientific management plan has been formulated, and the comprehensive management level of the library has been greatly improved, which has played a corresponding role in promoting the modernization of the school library. On the basis of analysis and research on library management in the new era, combined with the development needs of the times, we should carry out more scientific and systematic research on the management of school libraries, and provide for the reform of the comprehensive management of school libraries. The corresponding guidance.

\section{New changes in the development of school libraries in the Internet era}

The arrival of the information age has had an extremely important impact on the management of school libraries, which has caused certain changes in the basic content and main forms of the library in the process of carrying out management work. Therefore, the Internet era should be conscious and purposeful to the school. The new changes presented in the development of the library will be analyzed and researched, and the use of library functions will be strengthened in an all-round way to ensure that the school library will be promoted towards modernization, networking and digitization with the support of integrated management technology. The specific analysis, influenced by the wide application of Internet information technology, the new changes in the school library are concentrated and reflected from the following aspects: 


\subsection{The acquisition of document information presents an informational state}

Under the background of information age, the school library strengthens the application of computer technology and network technology in the process of construction and development, reforms and innovates the literature resource management work[1], tries to construct the corresponding literature database and CD management system, and puts a large amount of literature in Small database and management system storage, thus promoting the formation of electronic libraries, creating a certain convenience for readers to obtain relevant book information, and providing a platform for teachers and students to query information and use information, and promote information on document information resources. Exchanges to ensure that the quality of library literature resources services has been comprehensively and systematically enhanced.

\subsection{The document carrier presents a diversified development trend}

With the application of information technology becoming more and more extensive, the development of document information resources is more rapid. To a certain extent, traditional paper document carriers have been difficult to meet the needs of information storage in the new era. It is necessary to combine the application of computer technology and related storage. The development of technology has innovated the literature in the body. In the specific research, the current school library in China has explored the transformation of the literature information presentation carrier in the process of exploring information construction. $\mathrm{CD}$ and hard disk have become an important platform for storing data information, and electronic publications are in the library literature resources. The proportion of the middle is increasing, which has become an important form in the library literature resources, which has created favorable conditions for further improving the effective utilization rate of the literature resources of the school library.

\subsection{The network system shows the characteristics of sharing}

Based on the analysis of the traditional school library service model in China, it is found that due to the low level of technology, in the process of library construction and development, it is often only possible to provide library and material borrowing services for teachers and students and provide reading places. Relatively single, the use of literature resources also has obvious limitations. In the Internet age, with the support of information technology, the school library actively explores the digital construction of document resources, and in the process of building a digital library, the library network system has been continuously improved, to a certain extent Library document information management shows the characteristics of automatic sharing, which can realize the maximum utilization of library literature information resources, and has a corresponding positive impact on the comprehensive system to improve the comprehensive development of school libraries[2].

\section{The Internet era to innovate the school library management model}

The research and analysis on the basic development of the school library management mode in the Internet age can be seen that the innovation of the library management model can promote the stable development of the library and promote the social function of the library[3]. Therefore, in the current social background, combined with the needs of social development, in the process of reforming and innovating the integrated management model of the library, we must systematically examine the impact of the information age on the comprehensive management model of the school library, and then develop a more scientific library construction and The management plan accelerates the modernization and development of the school library and provides corresponding support and 
guarantee for the sustainable and stable development of the school library. Specific analysis, in the Internet era, in the process of reforming and innovating the school library management model, we can select the following angles for a more scientific and systematic interpretation.

\subsection{Introducing a new management model concept to provide guidance for innovation in management work}

The paper analyzes the traditional management mode of school libraries in our country and finds that it is influenced by many factors. In the process of traditional management of libraries, the collection of paper books is mainly based on the collection of teachers and students. The service also takes the paper literature as the core. The library's reader service function is relatively simple, and it is difficult to reform and innovate the service method according to the diversified needs of the book. At the same time, the collection and preservation of books is the main work content of the school library. The main work in the construction and development of the school library is the high quality preservation and management of books, and the reading needs of teachers and students are placed in a secondary position. In the process of library development, the function of society and the function of serving the teachers and students are weakening. Therefore, in the new era, in the era of the Internet, this traditional single management model has been difficult to meet the needs of the library's comprehensive management, it is necessary to try to innovate the backward management model, and introduce a new management concept to ensure that it can be combined with the extensive application of information technology. Diversified management mode, and gradually promote innovative and standardized development in library management. In the process of introducing new management concepts and guiding the construction of management models, we should try to introduce the "Internet + Library Management" model thinking, humanistic ideas and refined management concepts to ensure that we can fully grasp the needs of teachers and students. On the basis of reforming and innovating the school library management model, on the basis of meeting the needs of teachers and students, it explores the sharing and utilization of library document information resources to ensure that the library can truly play its social function in the development process. Promote the vigorous development of comprehensive reading activities to play a corresponding role, and effectively promote the enhancement of national quality[4]. In this way, under the background of the Internet era, the comprehensive management mode of the school library will be reformed and innovated, and a more scientific comprehensive management plan for the library will be formulated to make a correct ideological guidance for the modernization of the school library.

\subsection{Innovating the management and service mode of traditional school libraries}

In the process of building and developing a school library, if we want to formulate a scientific management and service model, we should systematically understand the shortcomings of the current management model, and then combine the application of Internet information technology and the reform of the traditional management model to make a more scientific Management plan to comprehensively improve the comprehensive development of library management. In the process of innovating specifically for the school library management service model, library managers should analyze the needs of the library service in the Internet era, clarify the important role of the library in document retrieval and sharing, and then pass the existing literature resources. Screening and screening, exploring the value of information resources, seeking management and service innovation models that are compatible with the development background of the times, and on the basis of repeated argumentation on current issues, propose ways to solve problems and effectively improve school books. The effect of integrated management and services. Based on this, in the process of construction and development, the school library should conduct a comprehensive and systematic 
analysis of the needs of teachers and students, and make appropriate adjustments to the library management work in light of the changes in the needs of teachers and students in the new era, and enhance the active service[5]. The consciousness changes from the traditional passive management to the active provision of services, that is, appropriate to provide the push information to the teachers and students according to the reading preferences of the teachers and students, and to share the new changes in the library management work to the teachers and students, etc. Let the teachers and students group to form a comprehensive and systematic understanding of the basic situation in the current library development process, and thus better participate in the library reading activities, and gradually realize the optimal use of library literature resources.

\subsection{Comprehensively building an integrated management model for information integration}

In the process of reforming and innovating the comprehensive management activities of the school library, in order to form a comprehensive and systematic understanding of the comprehensive development of the library and highlight the effect of library management, it should be combined with the application of information technology and the innovation of science and technology to the library. Document management and service models are appropriately innovated, and based on the challenges and opportunities faced by libraries in the context of the new era, management activities are adjusted, and an integrated management model for information integration is explored to truly realize the development goals of innovative management [6]. The specific analysis is that in the modernization activities of the school library, we should try to make appropriate adjustments to the organizational structure of the literature, and change the library management system to ensure the overall management of the literature information, and to create online and offline coordinated management. The new model, in turn, innovates the scientific management system model, realizes the effective integration of information, knowledge and intellectual resources. On the basis of promoting the modernization of the library, the library information update and the teacher and student group service work can develop with the new era. The needs are adapted.

Under normal circumstances, the update speed of literature information resources is relatively fast. In the process of human beings trying to explore knowledge update, it is necessary to better improve the literature information service, and then comprehensively and systematically implement education and training for library managers. It can be adapted to the service functions such as processing, editing, retrieval and query of book literature resources under the information integration management mode, and adopts effective incentive measures to make the innovative service consciousness and service idea of school library administrators fully and systematically stimulated. It truly integrates the knowledge quality and the ability and quality, and then ensures the speed of the exchange and dissemination of the literature information under the support of high-quality library managers, and builds a comprehensive optimization management between the literature resource system, the human resources system and the science and technology system. The model ensures that the important role of the information integration management model can be truly played, and the modernization and development of the school library is effectively promoted [7]. In this way, based on the application of Internet information technology and the comprehensive innovation of the library management model, it is possible to create a modern school library integrated management service model, and the library comprehensive management work can also be adapted to the needs of the times, and gradually realize innovative development. On the basis of this, it will create greater social benefits and create favorable conditions for the development of the national social education work and the gradual improvement of the national quality. 


\section{Conclusion}

In summary, the innovation of the school library management model in the context of the Internet era involves many aspects. Only by combining the guidance of modern management concepts, school library managers can comprehensively strengthen the application change management model of information technology. A good library comprehensive management system provides corresponding support and guarantee for the modernization of the library. Therefore, the system examines the construction and development of the school library. In the new era, it is necessary to formulate a more scientific management plan, provide corresponding guidance for the construction of the library, and accelerate the process of comprehensive management of the library.

\section{References}

[1] Su Dongli. Research on the Management Mode of School Libraries in the Internet Age. Decision Making Exploration (The second half of the month, Vol. 5 (2014), p.38-39.

[2] Lian Xiangli. Research on the Management Mode of School Libraries in the Internet Age. China Educational Technique and Equipment,Vol. 1 (2017) , p.67-68.

[3] Yin Huiqin. Management Mode of School Libraries in the Internet Age. Human Resources Management,Vol. 5 (2017), p.175-176.

[4] Li Xingtuan. Discussion on Improving the Quality of Book and Information Management Personnel in the Internet Age. Office Business, (2017) No. 17, p.158-158.

[5] Lin Ping. Research on the Construction of Library Management Information under the Internet Age. Library Information, Vol. 11 (2017) p.00041-00042.

[6] Han Jianming. Research on the Innovation of University Library Management Mode in the Information Age. Office Business, (2016) No. 21, p.162-162.

[7] Liu Xiaodong. Reflections on the Innovation of Digital Library Management Mode in the Information Age. China Management Information, (2016) No. 19, p.201-202.

\section{About the Author}

Cai Xiaofeng born1963.1 Male, Nanjing University, Jiangsu, associate research librarian, research direction: library information 